On the upper part load vortex rope in Francis turbine: Experimental investigation

This article has been downloaded from IOPscience. Please scroll down to see the full text article.

2010 IOP Conf. Ser.: Earth Environ. Sci. 12012053

(http://iopscience.iop.org/1755-1315/12/1/012053)

View the table of contents for this issue, or go to the journal homepage for more

Download details:

IP Address: 193.226.8.90

The article was downloaded on 03/09/2010 at 07:08

Please note that terms and conditions apply. 


\title{
On the upper part load vortex rope in Francis turbine: experimental investigation
}

\author{
C Nicolet ${ }^{1}$, A Zobeiri ${ }^{2}$, P Maruzewski $^{2}$ and F Avellan ${ }^{2}$ \\ ${ }^{1}$ Power Vision Engineering sàrl \\ Ch. des Champs-Courbes 1, CH-1024 Ecublens, Switzerland, \\ ${ }^{2}$ Laboratory for Hydraulic Machines, Ecole polytechnique fédérale de Lausanne, EPFL \\ Av. de Cour 33bis, CH-1007 Lausanne, Switzerland \\ E-mail: christophe.nicolet@powervision-eng.ch
}

\begin{abstract}
The swirling flow developing in Francis turbine draft tube under part load operation leads to pressure fluctuations usually in the range of 0.2 to 0.4 times the runner rotational frequency resulting from the so-called vortex breakdown. For low cavitation number, the flow features a cavitation vortex rope animated with precession motion. Under given conditions, these pressure fluctuations may lead to undesirable pressure fluctuations in the entire hydraulic system and also produce active power oscillations. For the upper part load range, between 0.7 and 0.85 times the best efficiency discharge, pressure fluctuations may appear in a higher frequency range of 2 to 4 times the runner rotational speed and feature modulations with vortex rope precession. It has been pointed out that for this particular operating point, the vortex rope features elliptical cross section and is animated of a self-rotation. This paper presents an experimental investigation focusing on this peculiar phenomenon, defined as the upper part load vortex rope. The experimental investigation is carried out on a high specific speed Francis turbine scale model installed on a test rig of the EPFL Laboratory for Hydraulic Machines. The selected operating point corresponds to a discharge of 0.83 times the best efficiency discharge. Observations of the cavitation vortex carried out with high speed camera have been recorded and synchronized with pressure fluctuations measurements at the draft tube cone. First, the vortex rope self rotation frequency is evidenced and the related frequency is deduced. Then, the influence of the sigma cavitation number on vortex rope shape and pressure fluctuations is presented. The waterfall diagram of the pressure fluctuations evidences resonance effects with the hydraulic circuit. The time evolution of the vortex rope volume is compared with pressure fluctuations time evolution using image processing. Finally, the influence of the Froude number on the vortex rope shape and the associated pressure fluctuations is analyzed by varying the rotational speed.
\end{abstract}

\section{Introduction}

The vortex rope precession frequency commonly corresponds to 0.2 to 0.4 times the turbine rotational frequency $n$, and may also induce pressure fluctuations in a higher frequency range between $2 \cdot n$ to $4 \cdot n$, for high specific speed turbines at upper part load range as described by Fisher in 1980[1], Dörfler in 1994[2] and Jacob in 1996[3]. Figure 1 presents a waterfall diagram of pressure fluctuations measured in the draft tube cone of a Francis turbine showing both part load pressure fluctuations and upper part load pressure fluctuations. Moreover, a "shock phenomenon" may occur in the same operating range and induce structural vibrations due to vortex rope impacts on the draft tube wall, see Dörfler [2]. Upper part load pressure fluctuations may also leads to resonance between harmonics of the vortex rope and the test rig, see Nicolet et al. [4]. Koutnik et al. [5] performed investigations for different rotational speeds but for the same operating point, i.e. assessing the Froude influence, and pointing out that the pressure fluctuations can occur even if the predominant amplitudes are not found at a frequency being a multiple of the vortex rope precession. Therefore, the origin of these pressure fluctuations cannot only be induced by the shock phenomenon. In addition, the physical modulation process was identified by Koutnik et al. [5] to be related to the elliptical shape of the vortex rope cross section observed on test rig at upper part load. The motion of the elliptical vortex rope at upper part load can be decomposed in precession movement with pulsation $\omega_{\text {rope }}$ and the self rotation of the vortex rope 
with pulsation $\omega_{\text {sr }}$ as it is illustrated in Fig. 2. Haban et al. [6] demonstrated that the elliptical shape of the vortex rope can be predicted by modal analysis of a simplified draft tube flow. Koutnik et al. [7] analyzed the influence of air injection and hydraulic circuit on the upper part load pressure fluctuations. The elliptical shape of the vortex rope was also investigated using PIV measurements by Kirschner et al. [8] on a simplified draft tube.

This paper is a contribution to the analysis of the upper part load pressure fluctuations by means of high speed camera visualization with synchronized measurement of pressure fluctuations. First, the test case and related experimental apparatus is described. Then, image post processing is used to derive vortex rope diameter time evolution and to compare with to synchronized pressure fluctuations. The influence of both sigma cavitation number and Froude number are analyzed to show the interaction between the upper part load fluctuations and the hydraulic circuit.

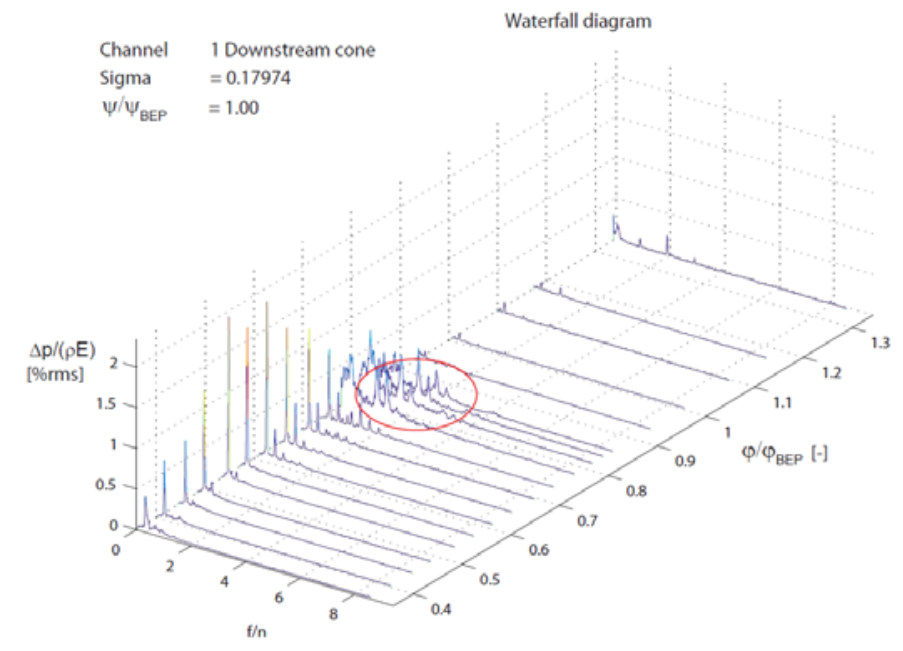

Fig. 1 Waterfall diagram of the pressure fluctuations measured at the downstream cone of the draft tube
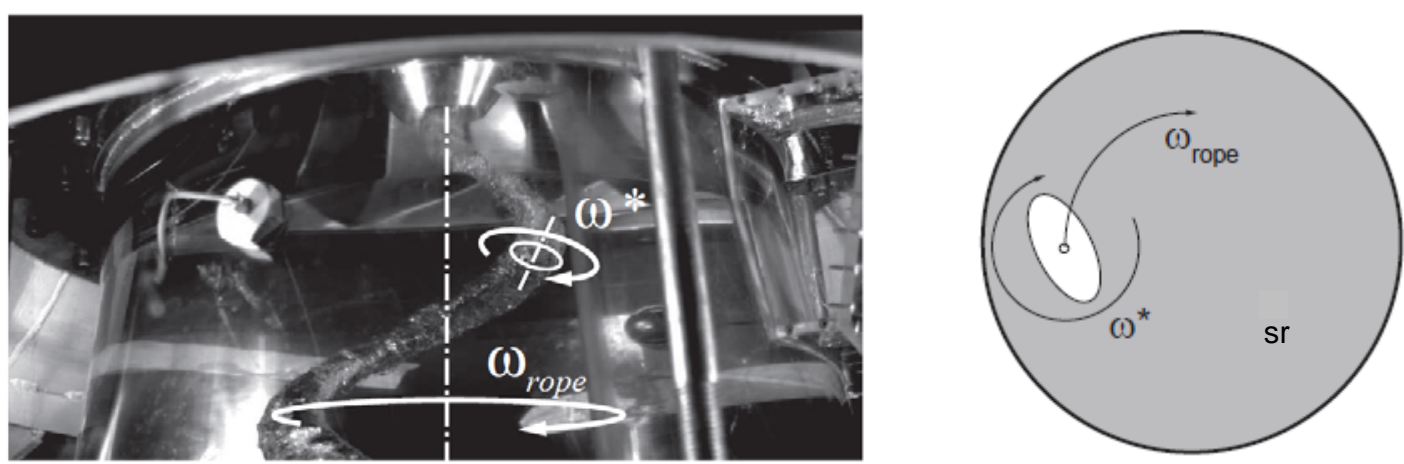

Fig. 2 Elliptical vortex rope precessing in the draft tube cone at upper part load

\section{Case study and experimental apparatus}

Pressure fluctuations measurements with synchronized draft tube vortex rope visualizations are carried out on a scale model Francis turbine with specific speed $v=0.5$ installed in EPFL test rig, see Fig. 3 . The waterfall diagram of the pressure fluctuations in the draft tube cone are presented in Fig. 1. The operating point featuring upper part load pressure fluctuation at rated discharge of $83 \%$ of the best efficiency point is selected for the experimental investigation and the related operating conditions are summarized in table 1.

To perform the visualization of the vortex rope, a high speed camera Photron is used. The frame rate used for the investigation is 4000 frames/seconds using a diaphragm aperture time of 1/4000 s and a number of 3600 frames per movie. The images are obtained with a resolution of $1024 \times 512$ pixels. The lighting is ensured by 2 continuous spot lights of $600 \mathrm{~W}$ each located at $45^{\circ}$ of each side of the high speed camera as shown in Fig. 3. The Francis turbine scale model is equipped with 3 wall Quartz pressure transducers Kistler 701A measuring the unsteady part of the pressure. Two pressure transducers are located in the draft tube cone and the third one is located in the spiral case inlet, see Fig. 3. The synchronization between the pressure acquisition and the image records is ensured by the trigger of an oscilloscope. The oscilloscope is used to store one second time history pressure signal with a sampling rate of 
$12.5 \mathrm{kHz}$. In parallel, the pressure is recorded using an HP 3566A PC Spectrum/Network Analyser system but without synchronization with the camera. These measurements are used for the representation of the waterfall diagram of the pressure fluctuations obtained by the averaging of 8 pressure amplitude spectra based on 4 seconds pressure time history with a sampling rate of $256 \mathrm{~Hz}$.

Table 1 Parameter of the scale model Francis turbine and investigated operating point

\begin{tabular}{|c|c|c|c|c|}
\hline \hline $\begin{array}{c}\text { Specific speed of the machine } v \\
{[-]}\end{array}$ & $\begin{array}{c}\varphi / \varphi_{B E P} \\
{[-]}\end{array}$ & $\begin{array}{c}\psi / \psi_{B E P} \\
{[-]}\end{array}$ & $\begin{array}{c}\mathrm{N} \\
{[\mathrm{rpm}]}\end{array}$ & $\begin{array}{r}\mathrm{GVO} \\
{\left[{ }^{\circ}\right]}\end{array}$ \\
\hline 0.50 & 0.832 & 1.00 & 700 & 21.5 \\
\hline
\end{tabular}

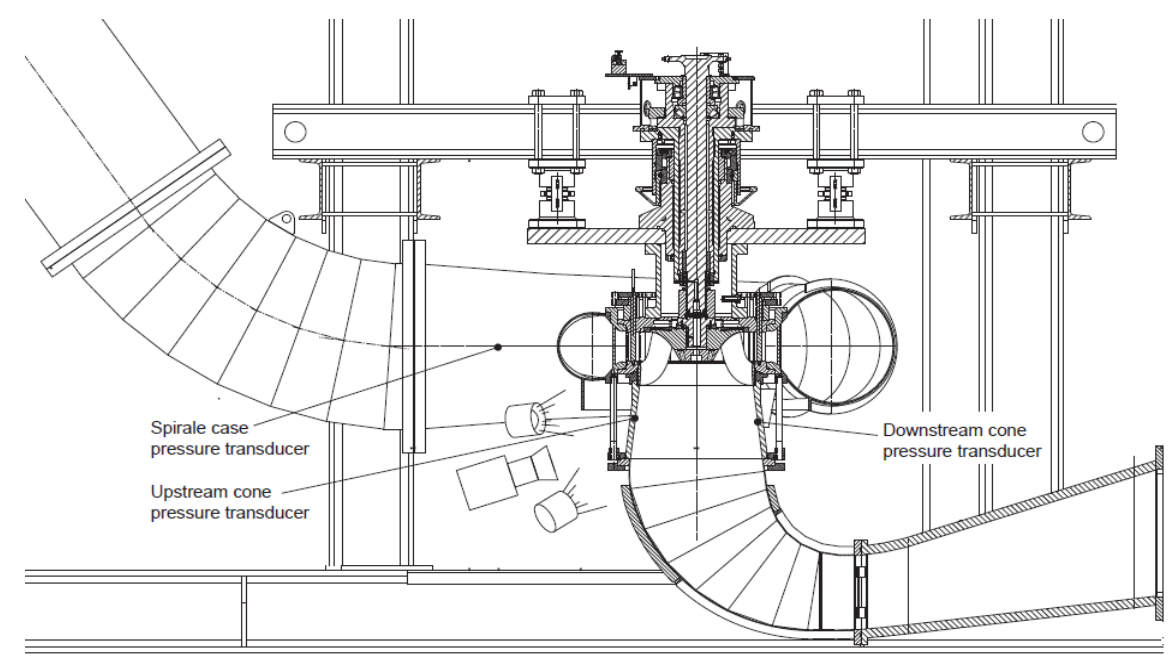

Fig. 3 Scale model installed on the EPFL test rig with high speed camera visualization

\section{Influence of the cavitation number}

The influence of the cavitation number $\sigma$, is analyzed for the operating point of

Table 1 by considering 6 different cavitation numbers varying from $\sigma=0.1$ to 0.3 and keeping the Froude number constant. The operating parameters as well as the observations are reported in the Table 2 .

Table 2 Operating parameters for the influence of the cavitation number $\sigma$

\begin{tabular}{|c|c|c|c|c|}
\hline \hline $\mathrm{N}^{\circ}$ & $\sigma[-]$ & Froude Number [-] & $\begin{array}{c}\mathrm{N} \\
{[\mathrm{rpm}]}\end{array}$ & Observation \\
\hline 1 & 0.30 & 8.47 & 700 & $\begin{array}{c}\text { Hydroacoustic resonance, } \\
\text { strong vortex rope shock on draft tube wall }\end{array}$ \\
\hline 2 & 0.26 & 8.47 & 700 & $\begin{array}{c}\text { Random hydroacoustic resonance, } \\
\text { vortex rope shock on draft tube wall }\end{array}$ \\
\hline 3 & 0.22 & 8.47 & 700 & \\
\hline 4 & 0.18 & 8.47 & 700 & Low inter-blade cavitation development \\
\hline 5 & 0.14 & 8.47 & 700 & Strong inter-blade cavitation development \\
\hline 6 & 0.10 & 8.47 & 700 & \\
\hline
\end{tabular}

The pressure fluctuations measured at the upstream cone, downstream cone and spiral case for the 6 different operating points are presented in Fig. 4 as a waterfall diagrams. It can be noticed that the frequency of the pressure fluctuations in the range of 1 to 3 times the rotational speed increases with the cavitation number, similar to [4]. The frequencies and amplitudes related to the upper part load pressure fluctuations are reported in Fig. 5. The frequency increases almost linearly with the cavitation number while the amplitude of the pressure pulsations rises quickly up to $2.5 \%$ of the specific energy $\mathrm{E}$ for $\sigma=0.3$. The amplitudes of pressure fluctuations for this cavitation number are 
similar for the 3 pressure transducers. In addition, strong mechanical vibrations and noise were noticed during the measurements. The shock phenomenon was also strongly present for these operating conditions. Thus, this operating point corresponds to the resonance between the vortex rope and the test rig.

Figure 6 left presents pictures of the vortex rope extracted from the movie synchronized with the pressure measurements presented on the top of the figure. This figure depicts the elliptical shape of the vortex rope self rotating at the pulsation $\omega_{\mathrm{sr}}$ and precessing with a pulsation $\omega_{\text {rope }}$ for the resonance operating conditions, i.e. $\sigma=0.3$. The five successive pictures extracted from the movie correspond to one period of the pressure fluctuations of interest $T^{*}$; from $t=t_{0}$ to $t=t_{0}+T^{*}$. Moreover, the influence of the pressure on the dimensions of the vortex rope appears clearly, as for $\mathrm{t}=$ to, when the pressure is high, the vortex rope features small diameter while the diameter is the highest for $\mathrm{t}=$ to $+\mathrm{T}^{*} / 2$ when the pressure is the lower. This pressure dependency is identical for the 6 operating points, see Nicolet [9]. Figure 6 right presents the same results for cavitation number $\sigma=0.22$ where it can be noticed that, as expected, the mean diameter of the vortex rope increases as the cavitation number $\sigma$ decreases. Moreover, the pressure fluctuations feature smaller amplitudes and a random like pattern. By analyzing the pictures of Fig. 6 it is found in agreement with Koutnik et al. [5], that the pulsation of the self rotation of the elliptical vortex rope $\omega_{\text {sr }}$ is half the pulsation of the measured pressure fluctuations $\omega^{*}$. Therefore, the combination between the rope precession $\omega_{\text {rope }}$ and the pressure fluctuations associated with the self rotation of the rope $\omega^{*}$, leads to the modulation process already described by Arpe [10]. The elliptical shape of the vortex rope makes apparent the non-uniformity of the pressure distribution in the cross section of the cone. Consequently, if the elliptical vortex rope rotates with the pulsation $\omega_{\text {sr }}$, the associated pressure fluctuation features a pulsation of $\omega^{*}=2 \cdot \omega_{\mathrm{sr}}$.

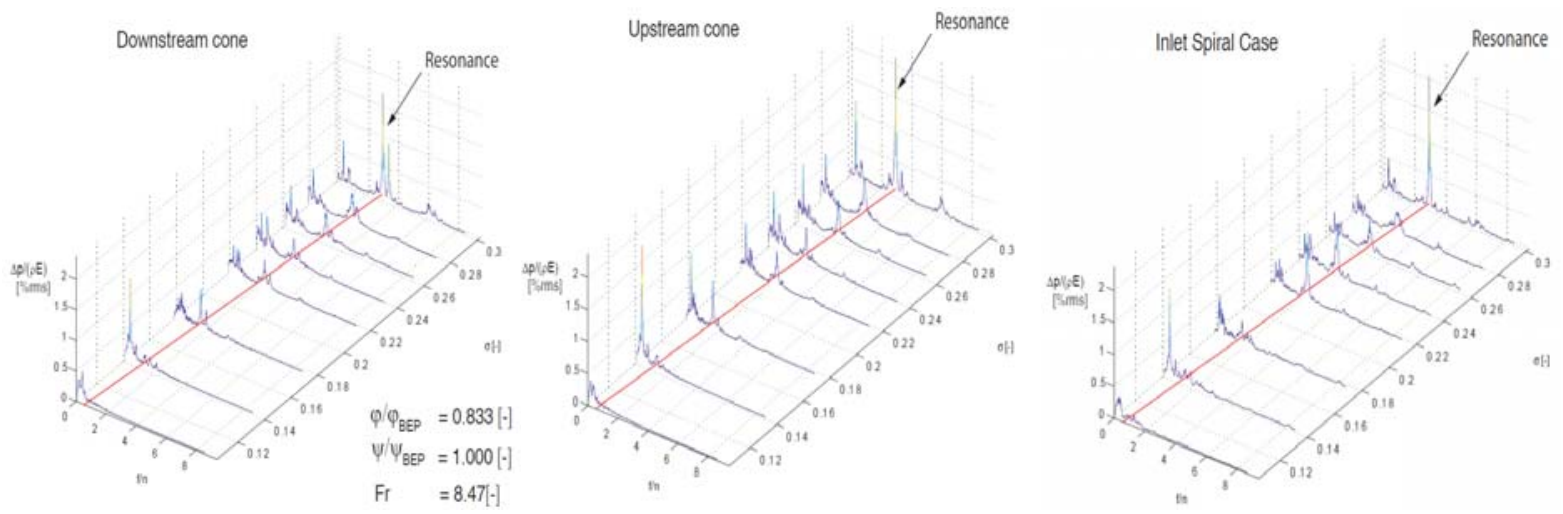

Fig. 4 Waterfall diagram of the pressure fluctuations measured at the downstream cone (left), upstream cone (center) and the spiral case (right) as function of the frequency and cavitation number

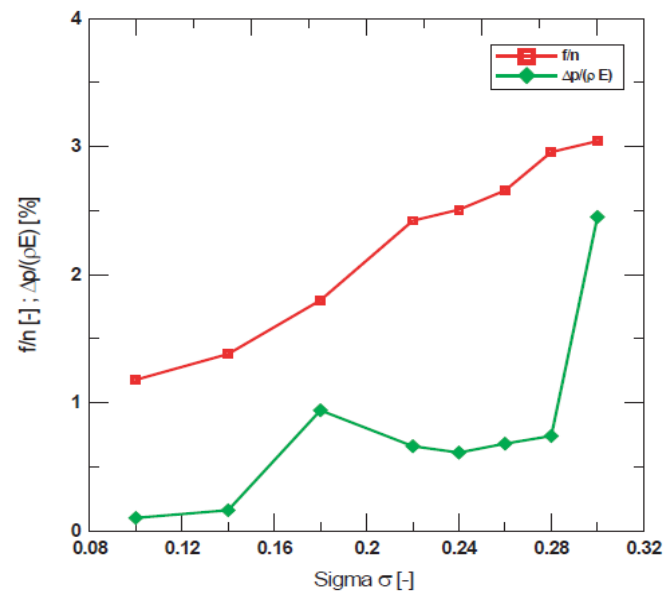

Fig. 5 Evolution of the frequency and amplitude of the pressure pulsations as function of the cavitation number at the downstream cone 

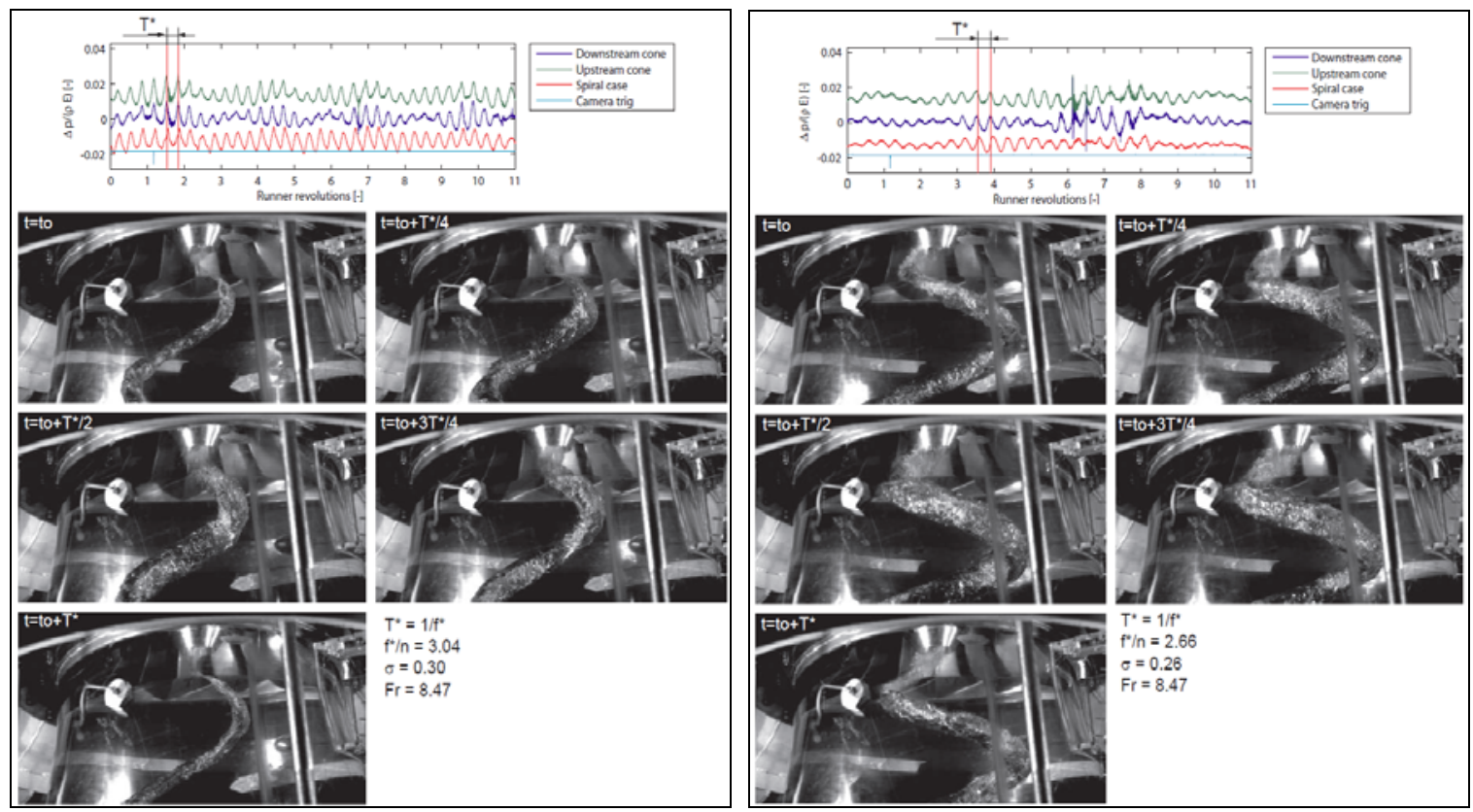

Fig. 6 Evolution of the vortex rope development for operating point $\mathrm{N}^{\circ} 1$ (left) and operating point $\mathrm{N}^{\circ} 2$ (right), see Table 2

\section{Vortex rope volume time evolution}

To confirm the influence of the pressure fluctuations on the vortex rope volume, the images of the movie related to operating point $\mathrm{N}^{\circ} 1$ with $\sigma=0.3$ are post processed. The post processing methodology is described in Fig. 7 . First, a part of the image focusing on the vortex rope is extracted. Then, the image is filtered in order to obtain black and white image of the vortex rope. The black area of the image $A_{b}$ and the white area of the image $A_{w}$ are computed in terms of pixels enabling to compute the ratio of white area as $A_{w} /\left(A_{w}+A_{b}\right)$. This ratio is representative of the vortex rope diameter. This image processing is carried out for all the 3600 images of the movie of operating point $\mathrm{N}^{\circ} 1$ with $\sigma=0.3$ and are presented as function of time in Fig. 8 left. The pressure fluctuation time history is presented in this figure and synchronized in time with the time evolution of the vortex rope volume using the camera start trig. It can be noticed that, as identified from Fig. 6, the volume of the vortex rope is always maximum when the pressure is minimum and vice versa. The period of the pressure fluctuations $T^{*}$ and the period of the vortex rope precession $T_{\text {rope }}$ can be clearly identified. Moreover, the ratio of white area calculated from image processing is represented as a function of the pressure in the draft tube and in spiral case for one period of pressure fluctuation $\mathrm{T}^{*}$ in Fig. 8 right. It can be noticed that the curves related to the pressure in the cone feature breathing like pattern and describe surfaces counter-clockwise indicating that the vortex rope is providing energy to the hydraulic system and behaves as an energy source.

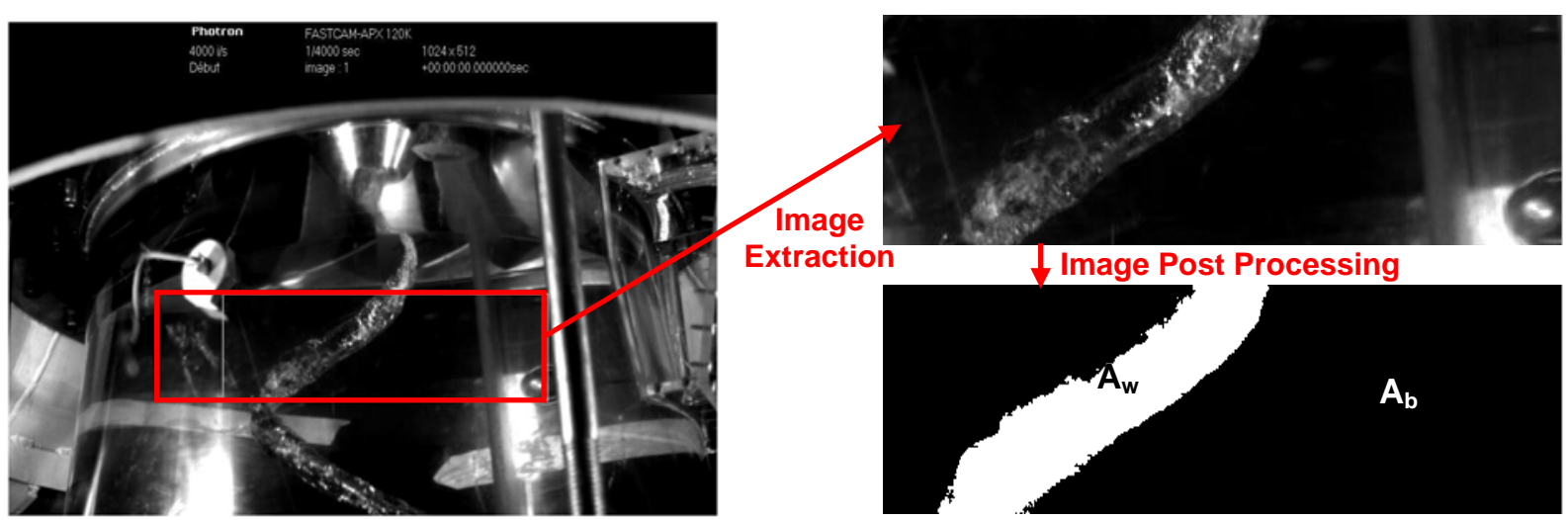

Fig. 7 Image post processing for vortex rope volume time history determination 

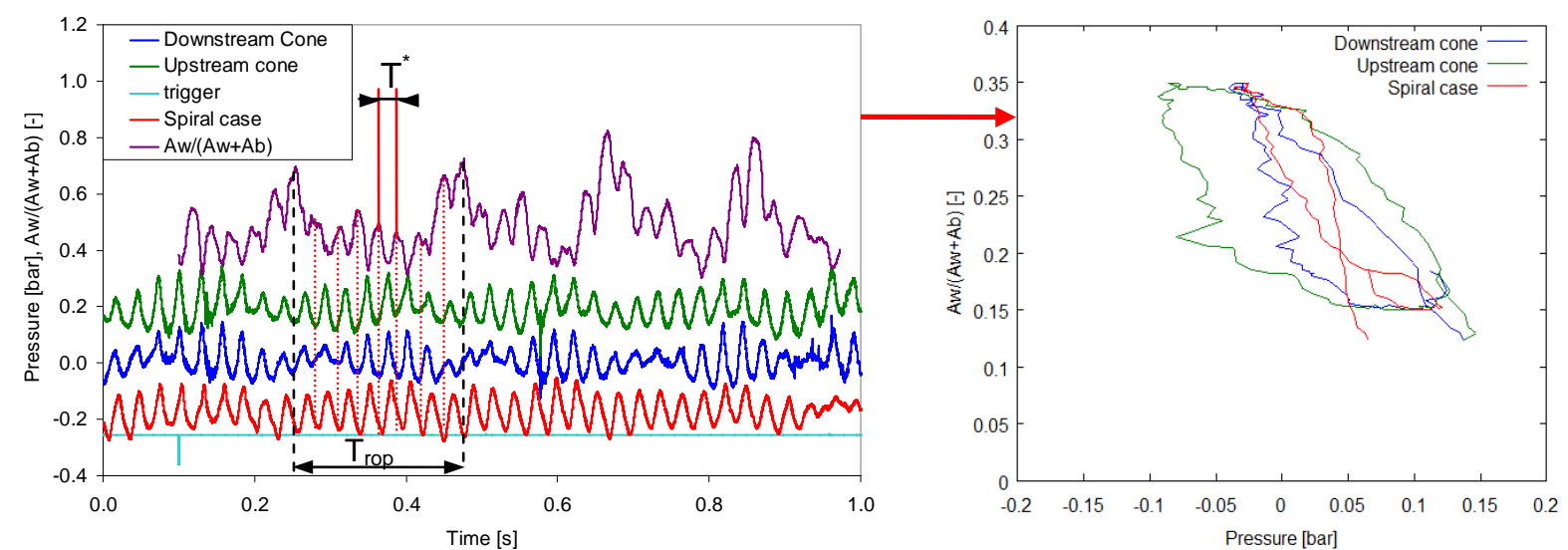

Fig. 8 Time evolution of the vortex rope area and synchronized pressure fluctuations (left) and vortex rope area versus pressure (right)

\section{Influence of the Froude number}

The operating conditions chosen for the investigation of the influence of the Froude number are identical as the previous operating point in terms of discharge coefficient and specific energy coefficient given in

Table 1, but the cavitation number is kept constant and equal to $\sigma=0.30$ in order to focus on the conditions of resonance of the test rig. The Froude number is given by $F r=C_{r e f} / \sqrt{g \cdot L_{r e f}}$ which can be expressed, considering the reference velocity as $C_{r e f}=\sqrt{E}$ as follows:

$$
F r=\sqrt{H / L_{r e f}}
$$

The Froude number affects the distribution of cavitation in the flow as it determines the pressure gradient relatively to the size of the machine. The relation between the position of the vapor pressure $p_{v}$ can be expressed as a function of the Froude number, see Franc et al. [11], neglecting Reynolds effects, assuming the same cavitation number $\sigma$ as a function of the reference position $Z_{\text {ref }}$ as follows:

$$
\frac{Z_{\text {ref }}-Z_{1}}{Z_{\text {ref }}-Z_{2}}=\frac{F r_{1}^{2}}{F r_{2}{ }^{2}}
$$

The Froude number being usually smaller on prototype than in the model, the elevation of the position of the cavitation is higher on prototype than in the model, [11], and [12]. Due to the difference of Froude numbers, the vortex rope on scale model is more narrow and longer than on prototype as illustrated in Fig. 9, see Dörfler [13].

For these investigations, four different values of the Froude number are taken into account and are obtained by varying the rotational speed of the turbine. The operating conditions considered for this investigation are presented in the Table 3. The wall pressure fluctuations measured at the downstream cone, upstream cone and spiral case are presented as function of the frequency and Froude number in Fig. 10 as waterfall diagram.

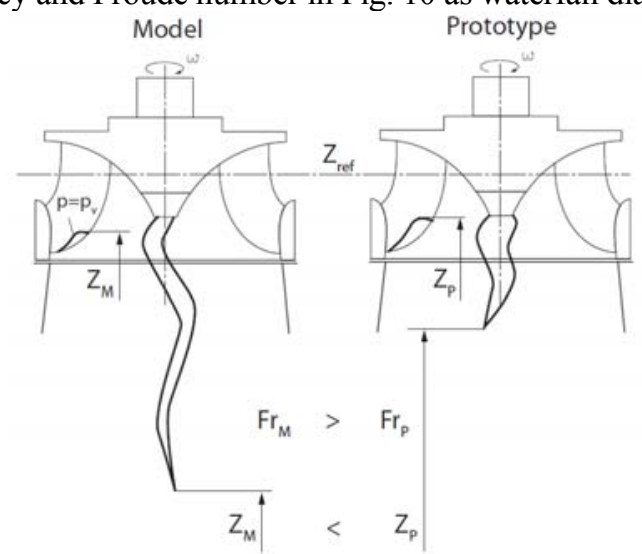

Fig. 9 Difference of the cavitation development between model $(M)$ and prototype $(P)$ due to difference in Froude numbers 
Table 3 Operating conditions for the influence of the Froude number

\begin{tabular}{|c|c|c|c|c|}
\hline \hline $\mathrm{N}^{\circ}$ & $\sigma[-]$ & Froude Number [-] & $\mathrm{N}[\mathrm{rpm}]$ & Remark \\
\hline 1 & 0.30 & 8.47 & 700 & $\begin{array}{c}\text { Hydroacoustic resonance, } \\
\text { and mechanical vibrations }\end{array}$ \\
\hline 7 & 0.30 & 7.86 & 650 & $\begin{array}{c}\text { Hydroacoustic resonance, } \\
\text { and mechanical vibrations }\end{array}$ \\
\hline 8 & 0.30 & 7.26 & 600 & $\begin{array}{c}\text { Low hydroacoustic resonance, } \\
\text { and mechanical vibrations }\end{array}$ \\
\hline 9 & 0.30 & 6.64 & 550 & $\begin{array}{c}\text { Low hydroacoustic resonance, } \\
\text { and mechanical vibrations }\end{array}$ \\
\hline
\end{tabular}

First, it can be noticed from the observations of Table 3 that hydroacoustic resonance and mechanical vibrations are observed for all tested conditions, even if the level of resonance and related vibration were lower for lower values of the Froude number. This is due to the fact that increasing the Froude number leads to a reduction of the specific energy and therefore of the absolute magnitude of the pressure fluctuations. However, as it is reported by the waterfall diagram of Fig. 10, the relative amplitudes of pressure fluctuations are not affected in the same way. Figure 11 represents the amplitude and frequency of the pressure pulsations of interest as function of the Froude number. It can be noticed that the frequency of the pressure pulsations are proportional to the runner rotational speed, in accordance with Koutnik et al. [7], and that the amplitudes are of the same order of magnitude for the values of Froude equal to $\mathrm{Fr}=8.47$ and 7.86 , while they are divided at least by a factor 2 for $\mathrm{Fr}=7.26$ and 6.64 . The reason is that the resonance phenomenon features more random behavior for $\mathrm{Fr}=7.26$ and 6.64 than for $\mathrm{Fr}=8.47$ and 7.86, see Nicolet [9]. Consequently the values obtained in the waterfall diagram are smaller for the higher values of Froude number.

No visualizations of the vortex rope are presented here as the shape of the vortex rope was not very much affected by the Froude number, at least in the range of tested Froude values, and therefore does not affect significantly the wave speed in the draft tube. It means that the eigen frequencies of the test rig, including the turbine and the draft tube, are not strongly affected by the change of the Froude number in the tested range. Then changing the rotational speed of the runner results in a mistuning between the excitation source, illustrated by the vortex rope self rotation, with associated pressure pulsation $\omega^{*}$, and the eigen frequency of the test rig. It results in a situation where there is no more strict resonance but random resonance. This means that the observed phenomenon is really of the resonance type. Similar conclusions have been found by Koutnik et al. [5] who found also a small part of self excitation observing the pressure versus rope volume dependence.

The modulation process between the vortex rope precession and the pressure associated with self rotation of the vortex rope, $f_{\text {rope }}$ and $f^{*}$ respectively, is illustrated by the amplitude spectra measured for $\mathrm{Fr}=7.86$. Therefore, the time plots and related amplitude spectra are represented in Fig. 12 where it can be clearly seen that modulation between the two dominant pulsations leads to amplitudes in the spectrum for $f=f^{*} \pm f_{\text {rope }}, f^{*} \pm 2 \cdot f_{\text {rope }}, f^{*} \pm 3 \cdot f_{\text {rope }}$, etc and for $f=2 \cdot f^{*} \pm f_{\text {rope }}, f^{*} \pm 2 \cdot f_{\text {rope }}, f^{*} \pm 3 \cdot f_{\text {rope }}$, etc. It can be noticed that in this case, the self rotation of the vortex rope corresponds to a multiple of the vortex rope precession frequency.

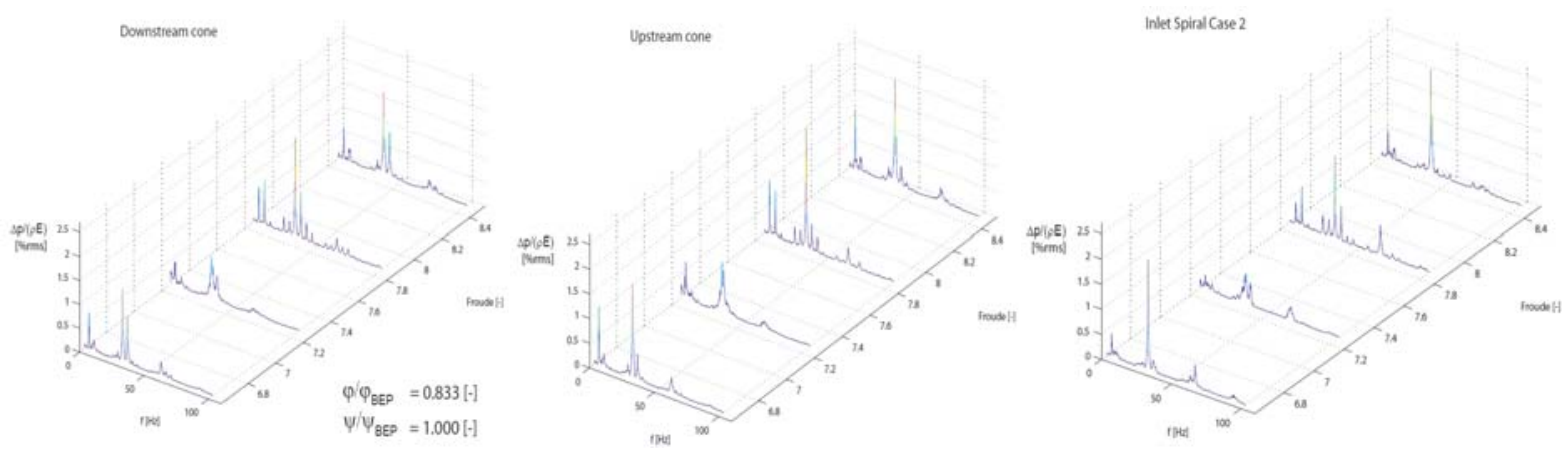

Fig. 10 Waterfall diagram of the pressure fluctuations at the downstream cone (left), upstream cone (center) and the spiral case (right) as function of the frequency and Froude number for $\sigma=0.3$ 


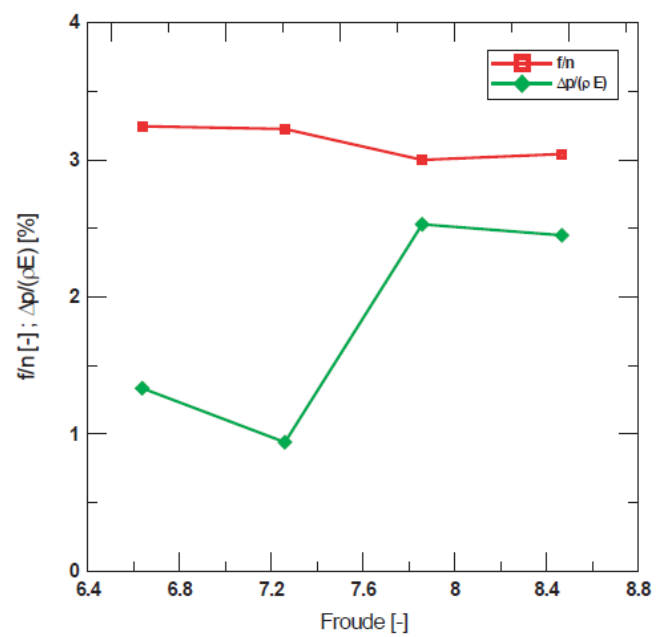

Fig. 11 Evolution of the frequency and amplitude of the pressure pulsations as function of the Froude number at the downstream cone for $\sigma=0$
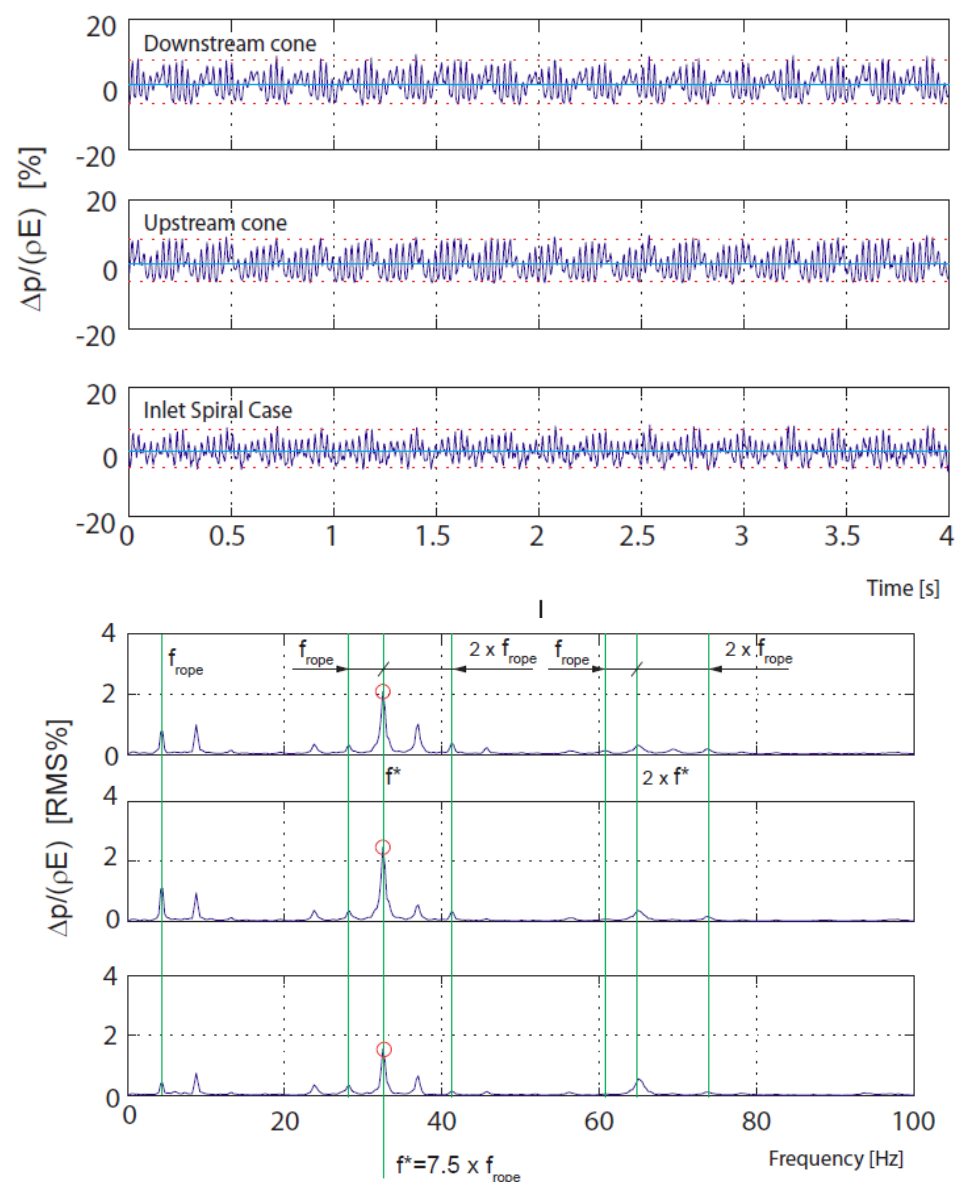

Fig. 12 Modulation of the pressure pulsation at the vortex rope precession frequency $f_{\text {rope }}$ and pressure pulsation $f^{*}$ for $\sigma=0.3$ and Froude $=7.86$

\section{Conclusion}

An experimental investigation on a reduced scale Francis turbine of specific speed $v=0.5$ was performed using wall pressure measurements synchronized with movie recording. The upper part load is characterized by pressure pulsations in the range of $\mathrm{f} / \mathrm{n}=1$ to 3 . The flow visualizations with simultaneous pressure 
measurements show that the vortex rope features an elliptical cross section and that the vortex rope is self rotating at a frequency half of pressure fluctuations of interest. This particular structure of the flow leads to modulation of the pressure fluctuations related to the vortex rope precession and of the pressure fluctuations of interest.

Image processing enabled to point out that the vortex volume is changing according to pressure and features breathing like pattern and behaves as an excitation source. The pressure fluctuations appear to be strongly linked to the cavitation number and therefore resonance conditions are commonly encountered during model tests when the excitation source of the vortex rope in the range of $f / n=1$ to 3 matches the hydraulic system eigen frequencies. The Froude investigation shows that the pressure fluctuation frequency is proportional to the rotational speed, and therefore the draft tube flow behaves as an excitation source but with excitation frequencies above the rotational speed.

\section{Acknowledgments}

The authors would like to thank Etienne Vuadens, Amborsio Acal Ganaza and Philippe Ausoni from LMH for their help in the setup of the acquisition system and signal post processing. The authors also would like to thank all the staff from the model testing group of the Laboratory for Hydraulic Machines, LMH, for their support for the set up of the experimental facilities.

\section{Nomenclature}

\begin{tabular}{|c|c|c|c|}
\hline$A$ & Image area, pixels & $p$ & Pressure, $\mathrm{Pa}$. \\
\hline$C$ & Absolute mean flow speed, $\mathrm{m} / \mathrm{s}, C=Q / A$ & $p_{v}$ & Vapor pressure, $\mathrm{Pa}$ \\
\hline$E$ & Machine specific energy, $\mathrm{J} / \mathrm{kg}, E=g H_{1}-g H_{2}$ & $g$ & Gravity acceleration, $\mathrm{m} / \mathrm{s}^{2}$ \\
\hline Fr & Froude number, & $\rho$ & Water density, $\mathrm{kg} / \mathrm{m}^{3}$ \\
\hline$H$ & Head, $\mathrm{m}$ & $\varphi$ & Discharge coefficient, $\varphi=Q / \pi \omega R_{r e f}^{3}$ \\
\hline$L_{\text {ref }}$ & Reference length, m & $\psi$ & $\begin{array}{l}\text { Specific energy coefficient, } \\
\psi=2 E / \omega^{2} R^{2}\end{array}$ \\
\hline$N$ & Rotational speed, rpm & & \\
\hline$Q$ & Flow rate, $\mathrm{m}^{3} / \mathrm{s}, Q=C \cdot A$ & $v$ & Machine specific speed, $v=\varphi^{1 / 2} / \psi^{3 / 4}$ \\
\hline$R_{r e f}$ & Machine reference radius, $\mathrm{m}$ & $\omega$ & Pulsation, $\mathrm{rad} / \mathrm{s}$ \\
\hline$T$ & Period, s & & Pulsation of the vortex rope precession, \\
\hline$Z$ & Elevation, $\mathrm{m}$ & $\omega_{\text {rope }}$ & $\mathrm{rad} / \mathrm{s}$ \\
\hline$f$ & Frequency, $\mathrm{Hz}, \quad f=1 / T$ & $\omega^{*}$ & Pulsation of vortex rope self rotation \\
\hline$f_{\text {rop }}$ & Frequency of the vortex rope precession, $\mathrm{Hz}$ & & pressure fluctuations, $\mathrm{rad} / \mathrm{s}$ \\
\hline & $\begin{array}{l}\text { Frequency of the vortex rope self rotation } \\
\text { pressure fluctuations, } \mathrm{Hz}\end{array}$ & $\sigma$ & $\begin{array}{l}\text { Cavitation number, } \\
=\left(p_{r e f}-p_{v}\right) / 1 / 2 \rho C_{r e f}^{2}\end{array}$ \\
\hline$n$ & Runner rotational frequency, $\mathrm{Hz}$ & $B E P$ & Best efficiency point \\
\hline
\end{tabular}

\section{References}

[1] Fisher R K, Palde U and Ulith P 1980 Comparison of draft tube surging of homologous scale models and prototype Francis turbines Proc. of the $10^{\text {th }}$ IAHR Symp. on Hydr. Mach. and Syst. (Tokyo, Japan) pp 541-56

[2] Dörfler P K 1994 Observation of the pressure pulsation on Francis model turbine with high specific speed J. of Hydropower and Dams 21-26

[3] Jacob T and Prenat J E 1996 Francis turbine surge : discussion and database Proc.of the $18^{\text {th }}$ IAHR Symp. on Hydr. Mach. and Syst. (Valencia, Spain) vol 2 pp 855-64

[4] Nicolet C, Arpe J and Avellan F 2004 Identification and modeling of pressure fluctuations of a Francis turbine scale model at part load operation Proc. of the $22^{\text {nd }}$ IAHR Symp. on Hydr. Mach. and Syst. (Stockholm, Sweden)

[5] Koutnik J, Krüger K, Pochyly F, Rudolf P and Haban V 2006 On cavitating vortex rope form stability during Francis turbine part load operation Proc. of the $1^{\text {st }}$ Meeting of the IAHR Int. Working Group on Cavitation and Dynamic Problems in Hydr. Mach. and Syst. (Barcelona, Spain)

[6] Habán V, Rudolf P, Pochylý F, Koutník J and Krüger K 2007 Stability of infinitely long asymmetrical vortex rope Proc. of the $2^{\text {nd }}$ IAHR Int. Meeting of the WorkGroup on Cavitation and Dynamic Problems 
in Hydr. Mach. and Syst. (Timisoara, Romania)

[7] Koutnik J, Faigle P and Moser W 2008 Pressure fluctuations in Francis turbines - theoretical prediction and impact on turbine Proc. of the 24th IAHR Symp. on Hydr. Mach. and Syst. (Foz do Iguassu, Brazil) p118

[8] Kirschner O, Ruprecht A and Göde E 2009 Experimental investigation of pressure pulsation in a simplified draft tube Proc. of the $3^{\text {rd }}$ IAHR Int. Meeting of the WorkGroup on Cavitation and Dynamic Problems in Hydr. Mach.and Syst. (Brno, Czech Republic) p B1 pp 55-64

[9] Nicolet C 2007 Hydroacoustic Modelling and Numerical Simulation of Unsteady Operation of Hydroelectric Systems PhD Thesis EPFL 3751 Lausanne (http://library.epfl.ch/theses/?nr=3751)

[10] Arpe J 2003 Analyse du champ de pression pariétale d'un diffuseur coudé de turbine Francis PhD Thesis (EPFL 2779 Lausanne)

[11] Franc J P, Avellan F, Belhadji B, Billard J Y, Brianc, Marjolet L, Fréchou D, Fruman D H, Karimi A, Kueny J L and Michel J M 1995 La Cavitation: Mécanismes Physiques et Aspects Industriels Collection Grenoble Sciences (Grenoble: Presse Universitaires de Grenoble) (in french)

[12] Jacob T 1994 Similitude in stability of operation tests for Francis turbine J. of Hydropower and Dams $\mathbf{I}$

[13] Dörfler P K 1982 System oscillations excited by the Francis turbine's part load vortex core: mathematical modeling and experimental verification $\mathrm{PhD}$ thesis Techn. University Vienna (Vienna, Austria) (in german) 